See Article page 502.

\section{Commentary: A nickel for your thoughts: An overlooked allergen in implantable devices?}

Phillip S. Naimo, MD, ${ }^{\mathrm{a}, \mathrm{b}, \mathrm{c}}$ and

Igor E. Konstantinov, MD, PhD, FRACS ${ }^{\mathrm{a}, \mathrm{b}, \mathrm{c}, \mathrm{d}}$

Nickel is a ubiquitous metal with a vast array of uses, ranging from household products to aerospace, military, and implanted medical devices. Its wide use is due to its corrosion resistance, durability, and ease at which it alloys with other metals. Currently, nickel allergy is the most common cause of contact dermatitis in the industrial world, affecting up to $20 \%$ of the population, particularly women. ${ }^{1,2}$ Many of these allergies manifest as dermatitis, but a subset of these patients may experience systemic symptoms. ${ }^{3}$ It is a growing health concern, so much so that nickel earned itself the title of "allergen of the year" in 2008. ${ }^{1}$ Until now, nickel may have been overlooked as a potential health problem causing systemic hypersensitivity.

The article by Sharma and colleagues ${ }^{4}$ in the current issue of the Journal describes the removal of nickel-containing atrial septal defect (ASD) closure devices in patients with nickel allergy and refractory symptoms. After device removal, patients experienced a resolution of symptoms and improved quality of life. This interesting study provides insight into a likely allergic process to occluder devices that contain higher proportions of nickel. ${ }^{4} \mathrm{~A}$ few comments seem appropriate to give some perspective to this article.

The possibility of nickel toxicity has been raised with the use of ASD closure devices, intracoronary stents, and pacemaker devices. ${ }^{5}$ Implantable devices are not uniform in

\footnotetext{
From the ${ }^{\text {a}}$ Department of Cardiac Surgery, Royal Children's Hospital, Melbourne, Australia; ${ }^{\mathrm{b}}$ Department of Paediatrics, University of Melbourne, Melbourne, Australia; 'Heart Research Group, Murdoch Children's Research Institute, Melbourne, Australia; and ${ }^{\mathrm{d}}$ Melbourne Children's Centre for Cardiovascular Genomics and Regenerative Medicine, Melbourne, Australia.

Disclosures: Authors have nothing to disclose with regard to commercial support.

Received for publication Nov 21, 2019; revisions received Nov 21, 2019; accepted for publication Nov 21, 2019; available ahead of print Dec 12, 2019.

Address for reprints: Igor E. Konstantinov, MD, PhD, FRACS, Royal Children's Hospital, Flemington Rd, Parkville, VIC 3052, Australia (E-mail: igor.konstantinov@ rch.org.au).

J Thorac Cardiovasc Surg 2020;160:512-4 0022-5223/ $\$ 36.00$

Crown Copyright $(2019$ Published by Elsevier Inc. on behalf of The American Association for Thoracic Surgery

https://doi.org/10.1016/j.jtcvs.2019.11.100
}

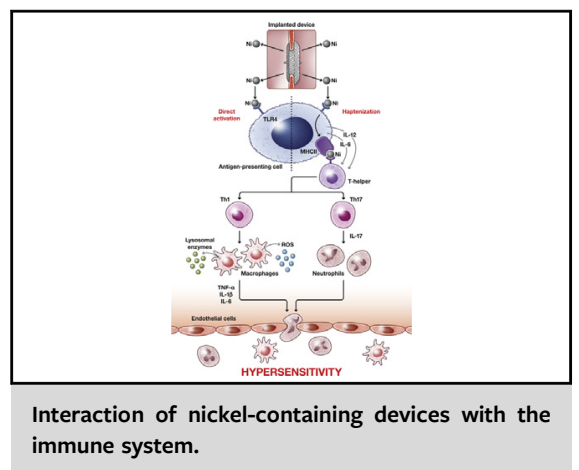

CENTRAL MESSAGE

Nickel allergy may present a sig-

nificant problem with some

implantable devices.

their composition, and there is a wide inter-device variability of nickel composition. Many devices contain nitinol, which is an alloy composed of $45 \%$ titanium and $55 \%$ nickel. Nickel in these devices has been shown to be released into the body, causing an increase in systemic nickel. ${ }^{6,7}$ In fact, during the first 6 weeks after device closure, serum nickel levels may increase up to 5 -fold. ${ }^{8} \mathrm{~Pa}-$ tients with a nickel allergy may experience dyspnea, headache, fatigue, and chest pain, ${ }^{6}$ which has been coined "device syndrome." Rigatelli and colleagues ${ }^{6}$ observed "device syndrome" within 2 weeks of ASD device closure and suggested that a low-level immunologic reaction was the cause of the phenomena, likely related to the nickel substance in the device, and this produced a mild leukocytosis.

However, implanted devices may have titanium alloy, platinum, and iridium, but also epoxy resins, polymethylmetacrylates, and isocyanates, all of which may be immunogenic in some patients. ${ }^{9}$ Furthermore, the metal strut in coronary artery stents is made from $316 \mathrm{~L}$ stainless steel, which contains nickel, as well as other endovascular prostheses and prosthetic valves. For example, the Edwards Magna Ease bioprosthetic aortic valve (Edwards Lifesciences, Irvine, Calif) and the Sapien transcatheter aortic valve (Edwards Lifesciences) have, among other alloys, approximately $15 \%$ nickel, in comparison with the pure nitinol frames of the Amplatzer device (St Jude, St Paul, Mo), in which the nickel concentration is approximately $55 \%{ }^{4}$ It may well be that the higher proportion of nickel in occluder devices provides a greater substrate for reactivity with the host immune system. It is interesting to note that clips 


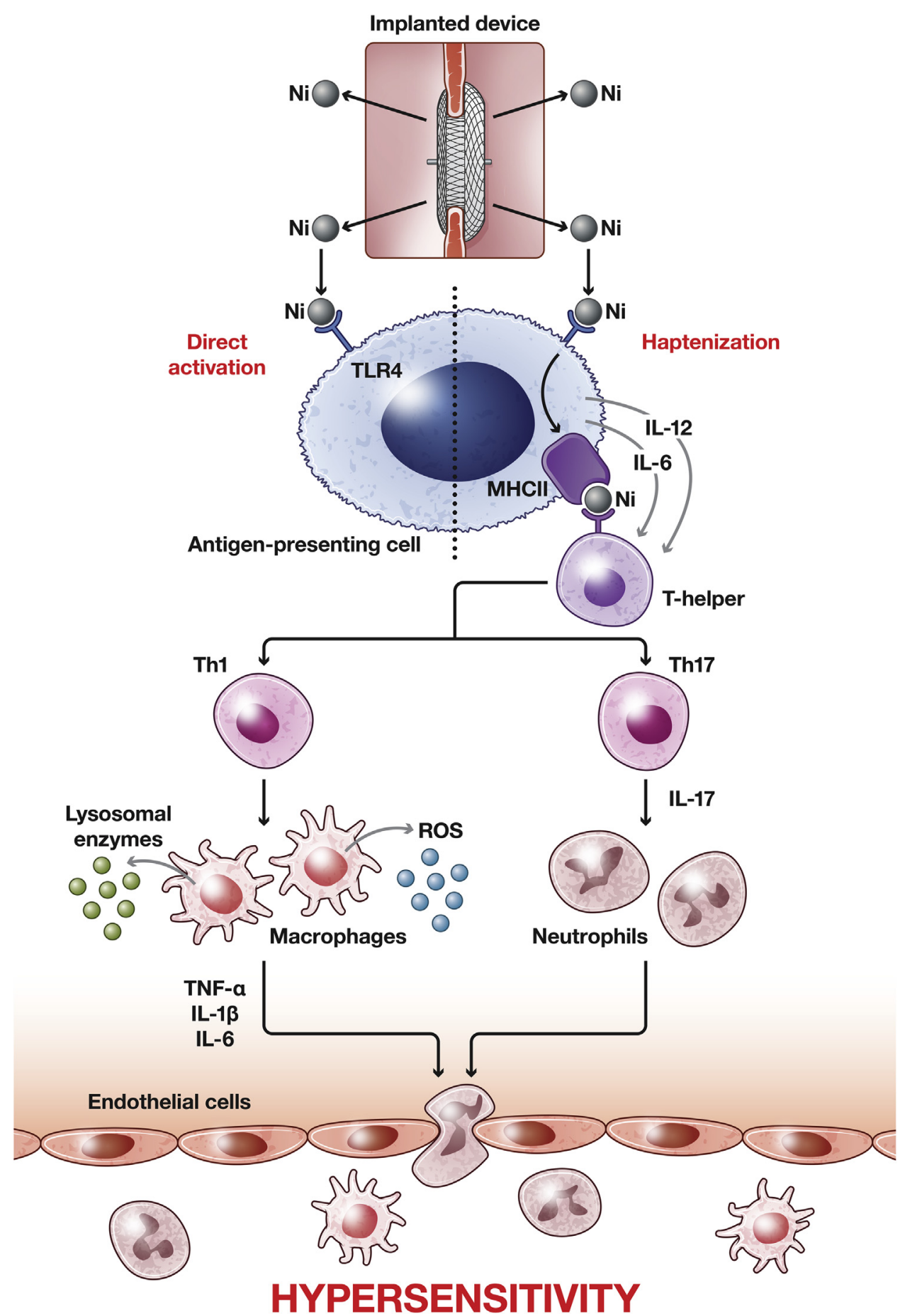

FIGURE 1. Interaction of nickel-containing devices with the immune system. Nickel ions are suggested to bind to toll-like receptor (TLR) 4 directly or are haptenized and interact with major histocompatibility complex (MHC) class 2 receptors, both of which can activate antigen-presenting cells (APCs). These activated APCs will subsequently present that immunogen to naïve T-helper (Th) cells ${ }^{12}$ and release cytokines (interleukin [IL]-12) that will cause the naïve Th cell to differentiate into type $1 \mathrm{~T}$ cells, Th1 cells. The Th1 cell will release several cytokines, including interferon- $\gamma$, which activates macrophages. The activated macrophages will release IL- $\beta$, IL-6, and tumor necrosis factor- $\alpha$, which cause expression of receptors on endothelial cells to recruit more leucocytes to the area. Activated macrophages release reactive oxygen species $(R O S)$ and toxic lysosomal enzymes; this causes tissue damage that can manifest itself in a variety of ways. The APCs may also release IL- 6 and other cytokines that cause naive Th cells to differentiate into Th17 cells. The Th17 cells release IL-17, which activates neutrophils in the area. Re-exposure to the same allergen would lead to the activation of specific T cells, which subsequently enter the bloodstream and produce visible signs of hypersensitivity at 48 to 72 hours after allergen exposure. ${ }^{13} I L$, Interleukin; Th, T helper; $T N F$, tumor necrosis factor. 
containing nickel, chromium, molybdenum, cobalt, and titanium can also induce allergic reactions and may be a cause of delayed wound healing. ${ }^{10}$

The underlying mechanism of a systemic nickel allergy is unclear. However, because nickel leaks into the bloodstream, it has been suggested that this may result in a type IV hypersensitivity reaction ${ }^{4,7}$ (Figure 1). Patients may have been previously sensitized to the allergen or this may occur de novo. The strength of this foreign body reaction is variable, and research continues into the question of why some patients have a more excessive response than others. Much of our understanding of nickel allergy comes from skin exposure to nickel in which the nickel ions penetrate the skin and activate epithelial cells that produce various cytokines, such as interleukin- $1 \beta$, interleukin-6, and tumor necrosis factor- $\alpha .{ }^{11-13}$

Although the best management of allergies is to limit exposure, this may not always be possible with some medical devices. In some cases, different devices may be used that contain a lower concentration of the offending metal ion. In other cases, the side effects can be managed with low doses of prednisolone and antiplatelet therapy. ${ }^{6}$ Yet, the best approach to any allergen is to remove the exposure to it. No device, no problem.

\section{References}

1. Kornik R, Zug KA. Nickel. Dermatitis. 2008;19:3-8.
2. Jacob SE, Moennich JN, McKean BA, Zirwas MJ, Taylor JS. Nickel allergy in the United States: a public health issue in need of a "nickel directive" J Am Acad Dermatol. 2009;60:1067-9.

3. Jensen CS, Menne T, Duus Johansen J. Systemic contact dermatitis after oral exposure to nickel: a review with a modified meta-analysis. Contact Dermatitis. 2006;54:79-86.

4. Sharma V, Skidmore CR, Glotzbach JP, Koliopoulou A, Javan H, McKellar, et al. Surgical explantation of atrial septal closure devices for refractory nickel allergy symptoms. J Thorac Cardiovasc Surg. 2020;160:502-9.e1.

5. Fukahara K, Minami K, Reiss N, Fassbender D, Koerfer R. Systemic allergic reaction to the percutaneous patent foramen ovale occluder. J Thorac Cardiovasc Surg. 2003;125:213-4.

6. Rigatelli G, Cardaioli P, Giordan M, Aggio S, Chinaglia M, Braggion G, et al. Nickel allergy in interatrial shunt device-based closure patients. Congenit Heart Dis. 2007; 2:416-20.

7. Ries MW, Kampmann C, Rupprecht H-J, Hintereder G, Hafner G, Meyer J. Nickel release after implantation of the Amplatzer occluder. Am Heart J. 2003; 145:737-41.

8. Burian M, Neumnn T, Weber M, Brandt R, Geisslinger G, Mitrovic V, et al. Nickel release, a possible indicator for the duration of antiplatelet treatment, from a nickel cardiac device in vivo: a study in patients with atrial septal defects implanted with an Amplatzer occluder. Int J Clin Pharmacol Ther. 2006;44: 107-12.

9. Pacheco KA. Allergy to surgical implants. JAllergy Clin Immunol Pract. 2015;3: 683-95.

10. Lhotka CG, Szekeres T, Fritzer-Szekeres M, Schwarz G, Steffan I, Maschke M, et al. Are allergic reactions to skin clips associated with delayed wound healing? Am J Surg. 1998;176:320-3.

11. Özçelik H, Vrana NE, Gudima A, Riabov V, Gratchev A, Haikel Y, et al. Harnessing the multifunctionality in nature: a bioactive agent release system with selfantimicrobial and immunomodulatory properties. Adv Healthc Mater. 2015;4: 2026-36.

12. Saito M, Arakaki R, Yamada A, Tsunematsu T, Kudo Y, Ishimaru N. Molecular mechanisms of nickel allergy. Int J Mol Sci. 2016;17:202.

13. Steinman RM, Pack M, Inaba K. Dendritic cells in the T-cell areas of lymphoid organs. Immunol Rev. 1997;156:25-37. 